\title{
Tierras indígenas en Brasil: análisis de juicios del Supremo Tribunal Federal
}

Indigenous Land in Brazil: Analysis of Federal Supreme Court Trials

\author{
Jorge Rubem Folena ${ }^{1}$ \\ Casa de América Latina
}

Brasil

\begin{abstract}
Resumen
El artículo fue redactado con base en una investigación que analiza diversos juicios realizados por el Supremo Tribunal Federal en asuntos de tierras indígenas, en Brasil, como en el caso de la reserva Raposa Serra do Sol. La metodología que se utilizó, fue la examinación de los votos y las manifestaciones de los jueces del Supremo Tribunal Federal, en los juicios relacionados con el tema. En esta investigación se ha verificado el comportamiento de un Supremo Tribunal Federal indiferente en relación con los indígenas brasileños, ante la crueldad con que fueron desalojados y expulsados de sus tierras ancestrales, mediante eventos practicados por invasores y por el propio Estado. Se puede afirmar que el comportamiento de los miembros del Supremo Tribunal Federal es el reflejo de una sociedad tan habituada a siglos de explotación que se ha vuelto incapaz de manifestar un gesto de repulsión delante del sufrimiento ajeno, con lo cual se aceptan con pasividad los actos de injusticia practicados contra sus semejantes.
\end{abstract}

Palabras clave: subalternidad; colonialismo; tierras indígenas; Supremo Tribunal Federal.

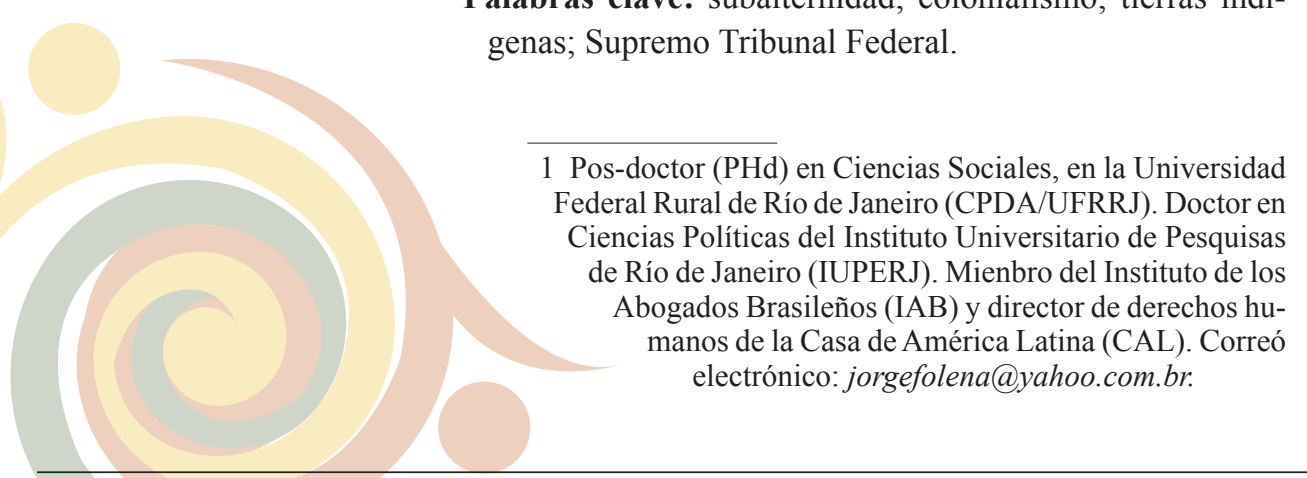




\begin{abstract}
The article was written based on an investigation that analyzes various trials conducted by the Federal Supreme Court on indigenous land issues in Brazil, such as the case of the Raposa Serra do Sol reserve. The methodology implemented was the examination of the votes and decisions of the judges of the Federal Supreme Court in the trials related to these issues. This investigation verified the behavior of an indifferent Federal Supreme Court in relation to the Brazilian indigenous people, in the face of the cruelty with which they were evicted and expelled from their ancestral lands, through practices carried out by invaders and by the State itself. It can be said that the behavior of the members of the Federal Supreme Court is a reflection of a society so accustomed to centuries of exploitation. This society has become incapable of expressing repulsion when it comes to the suffering of others; thereby, acts of injustice against fellow human beings are passively accepted.
\end{abstract}

Keywords: subalternity; colonialism; indigenous lands; Federal Supreme Court.

\title{
Luchar o perecer
}

A los pueblos indígenas, de Brasil y de otros lugares, apenas les resta "luchar o perecer”. Así lo manifestó Milla Elmiina Pulska, en una entrevista concedida a Sylja Kudel (2017) en referencia a la defensa de la preservación de su pueblo, los Sámi, pueblos indígenas que habitan territorios a lo largo de Noruega, Suecia, Finlandia y Rusia (países europeos con altísimos índices de desarrollo humano).

Los Sámi, durante generaciones, han sufrido ataques a su lengua, tierra e historia y viven en una situación de marginalización y subalternidad muy semejante a la experimentada por los diversos pueblos indígenas de Brasil.

De la misma forma que los demás pueblos originarios en el mundo, los Sámi han sufrido los efectos del colonialismo y racismo, como se demuestra en el artículo de Kudel (2017) ya que, la explotación económica de los territorios, ocupados por ellos, ha expulsado y masacrado a dichos pueblos.

En este punto, tuvimos la preocupación de plantear al debate la lucha del pueblo Sámi, cuyos territorios están situados en áreas hoy ocupadas por varios Estados nacionales europeos, teniendo en vista el hecho de que no son originarios de América Latina o de África; nuestro interés se justifica por la semejanza en la expropiación, más aún cuando Europa es considerada por algunos el "centro de la civilización", como lo imaginaba (Hegel 2010). 
En su lucha contra el colonialismo, los Sámi expresan (lo que también puede ser aplicado a nuestros pueblos indígenas) que nuestras selvas están aquí para darnos vida, no solo para ganar dinero (Kudel, 2017).

En el caso brasileño, el colonialismo, del pasado y del presente, trabaja con el propósito de exterminar a los pueblos indígenas y, de esta forma, despojarlos de sus tierras, para con ellas ganar dinero. En esta saga de emancipación, la lucha de los pueblos indígenas es contra el Estado brasileño y sus instituciones, que determinan su tutela, pero no los protegen; al contrario, les niegan el derecho natural de ocupar las tierras, donde viven desde hace miles de años, de donde retiran su sobrevivencia y en las cuales manifiestan su cultura.

Por lo tanto, la gran pregunta que se debe plantear es: “¿A quién le pertenece Brasil? (...) ¿Quién manda en la selva virgen, en el pantanal y en las pampas? ¿De quién es la tierra?" (Fedorov y Srapyan, 2018).

El recelo de responder a esas preguntas parece alcanzar a muchos ministros del Supremo Tribunal Federal, quienes, en algunas oportunidades, durante juicios vinculados a esa temática, permanecieron temerosos de reconocer, con sinceridad, que todas las tierras del país pertenecen a los pueblos indígenas.

Así, se niega el derecho originario de estos pueblos mediante el uso de argumentos simplistas, como el de Marco Aurélio de Mello, quien, en el juicio del caso de la reserva Caramuru-Catarina-Paraguaçu, localizada en la región sur del Estado de Bahía, afirmó que:

No estamos aquí para cuidar del rescate, considerada la violencia perpetrada en las tres Américas - del Sur, Central y del Norte - contra los indígenas, porque sería, imposible el retorno, por orden natural de las cosas, al estado anterior, cuando los indígenas realmente ocupaban, con exclusividad, las áreas territoriales. (...) Brasil todo consubstanció, a partir del descubrimiento, las tierras indígenas. Ni por eso podemos pensar en la desocupación, para entregar el territorio nacional a los indígenas. (Mello, 2012)

En idéntico sentido, Gilmar Mendes, en el juicio relacionado con la comunidad indígena Guyraroká, reconoció que los indígenas fueron expulsados de sus tierras, aunque se rehusó a determinar el retorno a su territorio originario, bajo el argumento de que tendría que "aceptar la demarcación de tierras en áreas donde están situadas antiguas aldeas indígenas en grandes ciudades de Brasil". (Mendes, 2016) 
Como se puede observar, la judicialización de la situación indígena no fue una buena opción para los movimientos que luchan en defensa de la causa indigenista, a ejemplo de lo observado en otros temas de gran repercusión política y social, cuya judicialización no tuvo efectos positivos, a pesar de ser una aparente causa ganada (Folena de Oliveira, 2016).

Considero que se debe tener mucho cuidado con la judicialización de temas vitales para los movimientos sociales, principalmente cuando se trata de asuntos relacionados con grupos o clases subalternas, que son llevadas hacia el orden estatal. Sin embargo, en el contexto histórico son tratadas como marginales, por ejemplo, el Movimiento de los Trabajadores Rurales Sin Tierra (MST) y los movimientos indigenistas, que luchan directamente contra la posesión de tierras públicas por parte de particulares o del poder económico de mineras.

En este trabajo, se demuestra que el peligro de la judicialización de temas políticos y sociales está bien retratado en el juicio del caso Raposa Serra do Sol, dado que, aparentemente, los indígenas salieron vencedores en la demanda judicial contra los ocupantes irregulares de sus territorios en Roraima. No obstante, sufrieron un revés judicial que les impuso una serie de limitaciones "condicionantes" (Direito, 2009), no previstas en la legislación, para explotar el territorio demarcado, en el cual, en estos casos, el Poder Judicial actúa como un legislador.

De la misma forma, la decisión estableció un "marco temporal", no detallado en el texto constitucional, que niega todo un pasado histórico de violencias practicadas contra los indígenas retirados por actos de Gobiernos o expulsados de sus tierras por invasores clandestinos, en una sucesión de hechos típicamente coloniales.

Así fue reconocido por el propio Supremo Tribunal Federal, expuesto por Eros Grau, que los indios Pataxós Hã-hã-hãe, Sapuyá, Baenã, Kariri y Kamakã fueron expulsados de sus tierras a costa de diversas formas de violencia, "desde la quemada de chozas y destrucción de plantaciones hasta castigos físicos, morales y psicológicos" (Grau, 2012). Ante tales decisiones, a los pueblos indígenas solo les queda resistir y luchar hasta el fin.

\section{1) El abrazo fraternal de un tribunal que alimenta la discordia}

En el juicio del caso de la Reserva Indígena Raposa Serra do Sol (Britto, 2009), localizada en el Estado de Roraima, fue dispuesto por el Supremo Tribunal Federal que el tema de la demarcación de tierras indígenas debería ser tratado como 
un "capítulo avanzado del constitucionalismo fraternal" (Britto, 2009); así lo expresó, en su voto, el ministro relator, Carlos Ayres Brito.

Este constitucionalismo fraternal, presentado por el Supremo Tribunal Federal, tuvo como fundamento el término "solidaridad", con el cual buscaba consumar "un nuevo tipo de igualdad civil moral de las minorías" (Britto, 2009). Dicho argumento, apropiado de la orden política hegemónica, tiene como base el consenso para acomodar los conflictos, sin presentar una solución efectiva para resolver los graves problemas sociales, que envuelven a los grupos o clases subalternas en un constante proceso de marginalización.

Por ejemplo, la Comisión Pastoral de la Tierra (CPT), por medio de informes de seguimiento, ha denunciado sistemáticamente la masacre ocurrida en el campo y el aumento de muertes de campesinos, cimarrones e indios. Según la Comisión Pastoral de la Tierra (CPT), este tipo de crimen es una estrategia más del capital para expulsar a los pueblos de sus tierras y de sus territorios (2017).

El "constitucionalismo fraternal" (Britto, 2009) se puede comparar, en este caso, al acecho de un animal, ya que lo que se observa, después del juicio del Supremo Tribunal Federal del caso Raposa Serra do Sol, es que los pueblos indígenas no han recibido ningún tratamiento solidario, ni por parte de los invasores de sus territorios, ni del Gobierno, ni del Legislativo, ni tampoco del Poder Judicial, que adoptó la expresión, a pesar de ver un permanente escenario de guerra y de desprecio hacia los indios

Esto se ha constatado, incluso con las incertezas lanzadas con la creación del llamado "marco temporal" de ocupación de la tierra por parte de los pueblos indígenas, establecido el 5 de octubre de 1988 (fecha de promulgación de la Constitución Federal), decidido en ese juicio (Britto, 2009). Sin embargo, el infeliz concepto "marco temporal" pasó a ser utilizado en otros juicios realizados por el Tribunal, a partir de 2014 (Mendes, 2014, e Teori, 2014), de manera contraria a los intereses de los indios, pese a que el nuevo relator del caso Raposa Serra do Sol, Luís Roberto Barroso (sucesor de Carlos Ayres de Britto), haya afirmado que "las referidas directrices (del caso) en la Reserva Indígena Raposa Serra do Sol no podrán ser objeto de cuestionamiento en otros procesos"(Barroso, 2013).

O sea, en un gesto típico de hegemonía y propio del (pos)colonialismo, el Supremo Tribunal Federal se contradice y actúa de forma diferente a lo antes manifestado, para favorecer los intereses de invasores de tierras indígenas, a cambio de beneficios comerciales de la denominada "agroindustria", al punto de permitir que el Gobierno Federal, durante la gestión de Michel Temer, reconociera 
el "marco temporal", en el ámbito administrativo, por medio del Parecer de la Abogacía General de la Unión (AGU) número 0001/2017.

La decisión del Supremo Tribunal Federal en el caso Raposa Serra do Sol, además de imponer condicionantes por el uso de la tierra, no respetó los orígenes de los pueblos indígenas ni los traumas de los despojos tutelados por el Estado. Estos dejaron a los indígenas vagando en busca de la tierra prometida, cada vez más difícil de alcanzar, a medida que "un nuevo tipo de igualdad civil moral de protección a la minoría" no es visto ni por la sociedad brasileña, ni tampoco por sus instituciones, al servicio de los intereses de los conquistadores del Estado, conforme reconoció la Organización de las Naciones Unidas (ONU) en un informe redactado a partir de su misión especial, en Brasil, de 2016, en el cual afirma que los ataques y asesinatos constituyen represalias en contextos de reocupación de tierras ancestrales por los pueblos indígenas después de largos atrasos en los procesos de demarcación (ONU, 2016).

\section{2) Poder público al servicio de invasores de tierras}

A ese paso, diversos hacendados que ocupaban, de forma irregular, áreas de la Reserva Indígena Raposa Serra do Sol, propusieron una acción popular para cuestionar su demarcación realizada por la Portería 534/2005, expedida por el ministro de justicia, y por el Decreto homologatorio de la reserva, firmado por el expresidente Luís Inácio Lula da Silva.

En el proceso, el Estado de Roraima manifestó su deseo de actuar como autor de la acción (¡al lado de los invasores de la reserva indígena!). Al principio, el pedido del Estado de Roraima fue rechazado por el Supremo Tribunal Federal; que, no obstante, le concedió el derecho de actuar en el proceso, como asistente de los invasores del área de la reserva indígena.

En esta parte, se observa que la estructura administrativa del Estado de Roraima fue manipulada por el poder político local, para favorecer los intereses particulares de los invasores del área de la Reserva Indígena Raposa Serra do Sol.

En efecto, una situación similar se observó en otros casos, como el de la acción judicial propuesta por el Municipio de Juti, en Mato Groso del Sur, que pretendía cuestionar la demarcación de tierras indígenas (Fux, 2017); o sea, el poder público municipal utilizó su aparato administrativo para pleitear por un asunto enteramente ajeno a su atribución constitucional, en beneficio de los intereses de particulares que ocupan las tierras de los indios. 
El Supremo Tribunal Federal, en el juicio de la Reserva Indígena Raposa Serra do Sol, afirmó que "al Poder Público, de todas las dimensiones federativas (Unión, Estados y Municipios), no le incumbe subestimar, ni mucho menos hostilizar a las comunidades indígenas brasileñas, sino aprovecharse de ellas para diversificar el potencial económico-cultural de sus territorios (de los entes federativos)" (Britto, 2009).

Al contrario de aquella orientación del Supremo Tribunal Federal, los entes federativos (Unión, Estados y municipios) han trabajado contra los intereses de los indios y a favor de políticas locales que benefician a invasores de tierras; efectivamente, tales entes subestiman y hostilizan a las comunidades indígenas, así como también a los campesinos, una dura y continua realidad en América Latina Linhares y Teixeira da Silva (1999, p. 68) describen el proceso de transferencia y conquista de tierras públicas en América Latina y en Brasil, a partir de la mitad del siglo XIX

Conforme un levantamiento realizado por el Consejo Indigenista Misionero (CIMI, 2016), en relación con más del $40 \%$ de las tierras indígenas, no se ha tomado ninguna medida por parte del Gobierno; se ha declarado apenas un 4,65 $\%$ y homologado un $1,23 \%$. Estos números demuestran la total desconsideración de las autoridades, de todos los poderes constituidos, de asegurar a los pueblos indígenas el derecho natural de tener acceso a la tierra y mantener sus tradiciones, aunque el Supremo Tribunal Federal haya manifestado claramente que las entidades federativas no deben subestimarlos.

En este ámbito, el informe de la misión especial de la ONU, que estuvo en Brasil en el 2016, afirmó, en relación con la estagnación de la demarcación de tierras indígenas en el mismo documento se menciona que hay una posibilidad de beneficios políticos en ciertos actores mediante la interpretación errada de "las implicaciones del proceso de demarcación de tierras indígenas para pequeños agricultores y municipios, lleva a la discriminación contra y al conflicto con pueblos indígenas" (ONU, 2016).

La decisión del Supremo Tribunal Federal parece no tener ninguna relevancia para los dirigentes políticos, que no expresan el mínimo interés en incentivar o aprovechar el potencial cultural de las comunidades indígenas. Esto porque el referido posicionamiento judicial apenas sirvió como orientación de principio, delante de un tema (invasión de tierra), cuyo origen se remonta a las luchas de colonización, en un panorama en el cual "persiste la discriminación contra y el conflicto con pueblos indígenas", como apuntó en el 2016 la Comisión Especial de la ONU. 
El uso de la estructura de las instituciones estatales, por parte del grupo político dominante, para conseguir sus propósitos privados, es una característica del patrimonialismo brasileño (arraigado en la estructura de los municipios brasileños, como describe Vitor Nunes Leal (2012), lo que, sin duda, significa una gran amenaza para los pueblos indígenas. Sin embargo, además de trabajar para librarse de la tutela de la Unión (que los representa jurídicamente), tienen que luchar contra los Estados y municipios brasileños, administrados y conducidos, en muchos casos, por intereses de los invasores de tierras públicas, lo que ha sido retratado por algunos romancistas como Jorge Amado (s. f), en las obras Tierras del sin fin, San Jorge de los Ilheus (Amado, 2012) y Gabriela Clavo y Canela (Amado, 2008).

La saga del pueblo indígena puede ser sintetizada por el mito de la cobra grande, del pueblo Katxuyana, (Miranda, 2005, p. 221) frente a los abusos practicados por el poder público, a favor de los invasores. En el contexto de la lucha por la posesión del suelo ancestral, sabemos que la verdadera serpiente es el Estado, preparado para, a todo momento, tragarse a los indios mediante su aparato burocrático.

\section{3) El temor de un territorio indígena libre y soberano}

El Supremo Tribunal Federal, en el juicio del caso Raposa Serra do Sol definió, para fines constitucionales, que "indio en proceso de aculturación permanece indio" (Britto, 2009), recibiendo la misma protección conferida a los denominados "silvícolas", quienes son "indios en proceso de habitantes de la selva". (Britto, 2009). Así lo entendió el ministro Nery da Silveira, en su voto a la Acción Civil Originaria número 278, en el cual, usando la característica típica del colonialismo que busca desvalorizar y humillar a los grupos subalternos, al tratar de los indios que habían sido despojados por el poder público hacia el Parque Nacional de Xingu, en Mato Groso, se refirió a ellos como "salvajes". (Silveira, 1983)

En el juicio de la Reserva Indígena Raposa Serra do Sol, los invasores de las tierras indígenas en la región lanzaron, de forma sensacionalista, la idea de que los indígenas tendrían como objetivo constituir una nación internacional soberana y libre, independiente del Estado brasileño (Britto, 2009). Sin embargo, al contrario de los pueblos indígenas, muchos hacendados no han manifestado ninguna preocupación con la integridad del territorio nacional, al abrir las fronteras de las tierras brasileñas a la agroindustria y a las mineras internacionales, que explotan las riquezas del país y las exportan sin tributación.

En los últimos años, se ha realizado un fuerte lobby, difundido por sectores ruralistas e incluso por órganos de los Poderes Constituidos. Estudio elaborado por el 
Núcleo de Estudios e Investigación del Senado, em un trabajo desarrollado por Hage, Pejeto y Vieira Filho (2012) concluye que:

La restricción impuesta por la legislación actual en relación a la adquisición de tierras por parte de extranjeros puede ser reducida e incluso inviabilizada una parte de las inversiones productivas en el sector agropecuario brasileño, en especial en los estados, cuya economía depende de ese segmento". Sin dejar ningún margen de dudas, se observa que la defensa está a favor de la liberación de la adquisición de tierras, por parte de extranjeros, que se origina en el órgano técnico del Senado Federal. (Hage, Pejeto y Vieira Filho, 2012, p. 30)

Para liberar la ampliación de venta de tierras en el campo a extranjeros; no se ha observado ninguna preocupación con la integridad territorial ni con la soberanía nacional, al contrario de lo discutido y decidido por el Supremo Tribunal Federal.

Al enfrentar esta cuestión en el juicio Raposa Serra do Sol, el Supremo Tribunal Federal entendió que las tierras indígenas, de acuerdo con la Constitución, "forman parte de un territorio estatal brasileño sobre el cual incide, con exclusividad, el derecho nacional" (Britto, 2009).

Así, el Tribunal abrazó la definición que provoca que "todas las tierras indígenas 'son un bien público federal” (Brito, 2009), sin que el territorio indígena extinga o restrinja el de un Estado federado, que pasa sobre las tierras de la reserva indígena. O sea, el Supremo Tribunal Federal, ratificando la expoliación iniciada en el proceso de colonización, fijó que las tierras indígenas no son de titularidad de los pueblos indígenas, ni se constituyen en territorio político o unidad federada de los indígenas.

Incluso, el Supremo Tribunal Federal, en el juicio Raposa Serra do Sol, definió que los indígenas ocupan una "tierra" y no un "territorio" (este sí protegido por una orden jurídica soberana), de grupos, organizaciones, comunidades o poblaciones indígenas que no constituyen una "persona federada" (Britto, 2009).

Con eso se estableció que los territorios indígenas, conforme la interpretación jurídica de la Constitución, no constituyen una entidad federada; además, se decidió que el Estado brasileño no concede "a cualquiera de las organizaciones sociales indígenas, al conjunto de ellas, o a su base peculiarmente antropológica, la dimensión de instancia transnacional" (Brito, 2009), siendo vetado a cualquier comunidad indígena brasileña "comparecer ante la orden jurídica internacional como 'nación', 'país', 'patria', 'territorio nacional' o 'pueblo independiente'” (Brito, 2009). 
Según la interpretación constitucional "fraternal" del Supremo Tribunal Federal Britto, 2009), las tierras ocupadas por los indios pertenecen a la Unión; siendo así, se autoriza a la clase política, que controla las instancias gubernamentales de poder, hacer con los pueblos indígenas - tutelados por ella - lo que bien entienda, a ejemplo de las suspensiones de todas las demarcaciones de tierra indígena. Con ello, se exponen los derechos de los indios y su autodeterminación, como ha sido observado en el informe de la Misión Especial sobre los derechos de los pueblos indígenas de la ONU, en agosto de 2016 declara que existen serios desafíos para los derechos de los pueblos indígenas, que los mismos se encuentran en un contexto de creciente discriminación, como se manifestó en protestas contra los pueblos indígena. Además, hubo una paralización de procesos de demarcación, incluyendo aproximadamente 20 demarcaciones de tierras pendientes de homologación presidencial y declaración ministerial, las consecuencias de lo anterior fueron desalojos en curso y constantes amenazas de nuevos desalojos.

En el mismo documento se continúan mencionando que hay profundos y crecientes impactos de grandes proyectos localizados dentro y bastante cerca de los territorios indígenas, seguidamente menciona que son implementados sin pertinentes y adecuadas consultas previas para obtener consentimiento libre, previo e informado de los pueblos afectados. Por ende, lo anterior repercute en: "violencia, racismo, asesinatos, amenazas e intimidaciones perpetradas con impunidad contra pueblos indígenas y aquellos que trabajan con ellos; inadecuada protección de las comunidades indígenas y sus líderes y el crecimiento de la frecuente alegación criminal contra ellos"(ONU, 2016).

La demarcación de territorios indígenas representa la necesidad de proteger a las minorías y debería estar insertada en el espíritu de la finalidad "fraternal" o "solidaria" de la Constitución, ya que los indígenas necesitan "disfrutar de un espacio agrario que les asegure medios dignos de subsistencia económica para poder, eficazmente, preservar su identidad corpórea, lingüística y cultural" (Britto, 2009), como consta en la enmienda del acuerdo del juicio de la Reserva Indígena Raposa Serra do Sol.

Lo previo significa que el Supremo Tribunal Federal reconoce que solamente la demarcación de tierras podrá garantizar la sobrevivencia de los indígenas, como grupo social minoritario; así, les corresponde "a los propios indios, decidir sobre su presente y su futuro" (Barroso, 2013). Sin embargo, como es propio de la imposición colonial, en razón de la conducción del referido juicio, no se rompió con el pasado explotador, que se impone a la subalternidad, y se votó para mantener a los pueblos indígenas en dependencia del Estado brasileño, sin autonomía para 
administrar sus tierras y a merced del poder público, con respecto a la necesidad de demarcación y homologación de sus reservas, única forma establecida para tener acceso a su derecho a esas tierras.

Los indios, al contrario de lo manifestado por el Supremo Tribunal Federal, no tienen el derecho de "decidir sobre su presente y su futuro"; por eso, la decisión del caso Reserva Indígena Raposa Serra do Sol, de modo opuesto a lo pretendido, sembró aún más la incertidumbre, en relación con la mantención de la vida presente, e intensificó la resistencia contra su exterminio completo, mientras tengan fuerzas.

Incluso después del juicio del caso Raposa Serra do Sol, realizado en marzo de 2009, en el cual los indios fueron los grandes derrotados (en oposición a lo que anuncian los invasores de sus tierras), se difunde el temor de que los pueblos indígenas puedan constituir un territorio libre y soberano. No obstante, frente a los números presentados por el Consejo Indigenista Misionero, en su Informe sobre Violencia Contra los Pueblos Indígenas en Brasil (CIMI, 2016), se observa que los indios, hasta hoy, no han tenido el derecho de vivir en paz ni cuentan con los "medios dignos de subsistencia económica para poder, eficazmente, preservar su identidad corpórea, lingüística y cultural” (Britto, 2009).

\section{4) Los condicionantes del miedo}

El juicio del caso Raposa Serra do Sol no calmó los ánimos de los invasores, que continuaron manipulando la idea de que los indígenas podían constituir un Estado "independiente" y "libre", cuando, en verdad, ellos no han tenido ningún derecho respetado por el Estado brasileño. Un informe sobre la violencia contra los pueblos indígenas en Brasil, del Consejo Misionero Indigenista (2016), revela la cruel mortalidad en la infancia, los suicidios, los asesinatos, la omisión y la morosidad en la regularización de tierras de los pueblos indígenas, lo que deja aún más evidente que a los indígenas no se les ha asegurado el derecho natural de vivir y cultuar sus valores ancestrales.

En el juicio de los recursos de embargos de declaración vinculados al caso Raposa Serra do Sol (Barroso, 2013), bajo la nueva relatoría de Luís Roberto Barroso (sucesor de Ayres de Britto, quien se jubiló), el Supremo Tribunal Federal afirmó que la decisión de 2009 no se relaciona (de forma obligatoria) ni a jueces ni a juicios de tierras indígenas diversas; lo que, al principio, podría ser favorable a los pueblos indígenas, principalmente en lo concerniente a las incertidumbres causadas por la definición del marco temporal de ocupación de las tierras, lanzadas en el juicio inicial. Sin embargo, no es lo que se ha verificado en el mismo Supremo 
Tribunal Federal, ya que, en otros juicios diversos, sus ministros han utilizado el argumento del "marco temporal", decidido primero en el caso Raposa Serra do Sol, para ilustrar su posición a favor o en contra de los pueblos indígenas. A modo de ejemplo, lo que se vio en los votos de Carmen Lúcia, en el caso de la reserva Caramuru-Catarina-Paraguaçu (Lúcia, 2012); de Teori Zavascki, en el caso de la Tierra Indígena Limão Verde (Teori, 2014), y de Gilmar Mendes, en el caso de la Tierra Indígena Guyraroká (Mendes, 2014).

En el juicio de los recursos de embargos de declaración del caso Raposa Serra do Sol (Barroso, 2013), el Supremo Tribunal Federal tenía como objetivo aclarar todas las dudas persistentes en el juicio anterior (Britto, 2009), en el cual, el Tribunal, por medio del voto del ministro Menezes Direito, estableció una serie de condicionantes (diecinueve en total), que se resaltan seguidamente:

1 - El usufructo de las riquezas del suelo, de los ríos y de los lagos existentes en las tierras indígenas puede ser relativizado siempre que haya, como lo dispone el artículo 231 (párrafo $6^{\circ}$, de la Constitución Federal) el relevante interés público de la Unión, en forma de Ley Complementar;

2 - El usufructo de los indios no abarca el aprovechamiento de recursos hídricos y potenciales energéticos, que dependerá siempre de la autorización del Congreso Nacional;

3 - El usufructo de los indios no abarca el estudio ni la labra de riquezas minerales, que dependerá siempre de autorización del Congreso Nacional, asegurando a los indios su participación en los resultados de la labra, en forma de ley;

4 - El usufructo de los indios no abarca la mineralización, ni la búsqueda de metales preciosos, se debe, si es el caso, obtener un permiso de labra garimpeira;

5 - El usufructo de los indios no se sobrepone al interés de la Política de Defensa Nacional. La instalación de bases, unidades, puestos militares y demás intervenciones militares, la expansión estratégica de la red viaria, la explotación de alternativas energéticas y el resguardo de riquezas, de carácter estratégico, serán implementados según el criterio de los órganos competentes (Ministerio de Defensa, Consejo de Defensa Nacional), independiente de consulta a comunidades indígenas envueltas y a la Funai; 
6 - La actuación de las Fuerzas Armadas y de la Policía Federal en el área Indígena, conforme sus atribuciones, será garantizada, independiente de consulta a comunidades indígenas envueltas y a la Funai;

7 - El usufructo de los indios no impide la instalación de equipamientos públicos por parte de la Unión Federal, redes de comunicación, carreteras y vías de transporte, además de las construcciones necesarias para la prestación de Servicios públicos, principalmente, de salud y de educación;

8 - El usufructo de los indios en el área afectada por unidades de conservación queda bajo la responsabilidad inmediata del Instituto Chico Mendes de Conservación de Biodiversidad;

9 - El Instituto Chico Mendes de Conservación de Biodiversidad responderá por la administración del área de la unidad de conservación, también afectada por la tierra indígena, con la participación de las comunidades indígenas de la zona, las cuales deberán ser oídas, considerando su uso, sus tradiciones y sus costumbres, y, para tanto, podrá contar con la consultoría de la Funai;

10 - El tránsito de visitantes y estudiosos no indios a la unidad de conservación debe ser autorizado en el área afectada, en horarios y condiciones estipulados por el Instituto Chico Mendes;

11 - Será admitida la entrada, el tránsito, la permanencia de no indios al resto del área de la tierra indígena, según las condiciones establecidas por la Funai;

12 - La entrada, el tránsito y la permanencia de no indios no será objeto de cobranza de tarifas o cuantías de cualquier naturaleza por parte de las comunidades indígenas;

13 - La cobranza de tarifas o cuantías de cualquier naturaleza tampoco podrá incidir o ser exigida a cambio del uso de carreteras, equipamientos públicos, líneas de transmisión de energía o de cualesquier otros equipamientos e instalaciones colocadas a servicio del público, incluso en el caso de que hayan sido excluidos expresamente de la homologación;

14 - Las tierras indígenas no podrán ser objeto de arrendamiento o de cualquier acto o negocio jurídico, que restrinja el pleno ejercicio del usufructo y de la posesión directa por la comunidad indígena; 
15 - Está vedada, en las tierras indígenas, la práctica de caza, pesca o colecta de frutas, así como de actividad agropecuaria extractiva, por cualquier persona extraña a los grupos o comunidades indígenas;

16 - Las tierras bajo ocupación y posesión de grupos y comunidades indígenas, el usufructo exclusivo de las riquezas naturales y de las utilidades existentes en las tierras ocupadas, así como la renta indígena según lo dispuesto en el artículo 49, XVI, y 231, párrafo $3^{\circ}$, de la Constitución de la República, gozan de plena inmunidad tributaria, no cabiendo la cobranza de cualesquier impuestos, tasas o contribuciones sobre unos y otros;

17 - Está vedada la ampliación de la tierra indígena ya demarcada;

18 - Los derechos de los indios relacionados a sus tierras son imprescindibles y estas son inalienables e indisponibles;

19 - Se asegurará la efectiva participación de los entes federativos en todas las etapas del proceso de demarcación. (Direito, 2009)

Tales condicionantes limitan la posesión y el ejercicio del usufructo por ser ejercido por los indígenas en áreas demarcadas administrativamente; incluso, el Supremo Tribunal Federal establece — como si legislador fuese- que territorios demarcados no podrían ser ampliados (condicionante número 17), motivo de cuestionamiento de la Procuraduría General de la República a favor de los indígenas.

O sea, los pueblos indígenas no tienen ninguna autonomía de acción sobre las áreas de las reservas demarcadas y homologadas, lo que establece su tutela permanente por parte del Estado y de su aparato burocrático (Ministerio Público Federal, Fundación Nacional del Indio, Policía Federal, Fuerzas Armadas, Instituto Chico Mendes de Conservación de la Biodiversidad, etc.); así aflora, de manera continua, el fantasma de la negación a autodeterminar estas etnias.

Las citadas condicionantes (Direito, 2009) impuestas y acogidas por el plenario del Supremo Tribunal Federal, mediante el voto presentado por Carlos Alberto Menezes Direito, reflejan el cambio ocasionado por la intensificación de la judicialización de la política, en que el Poder Judicial pasó a dictar (fuera de su real competencia institucional) la forma de proceder de la sociedad, constatado a partir de 2008, en diversos juicios realizados por el Supremo Tribunal Federal, Folena de Oliveira (2016):

La judicialización de la política es el fenómeno por el cual la sociedad, representada por partidos políticos, por el Ministerio Público, por los 
sindicatos, asociaciones o entidades de clase en general, se ha dirigido al Poder Judicial, en especial al Supremo Tribunal Federal (STF), solicitando que se manifieste sobre materias de naturaleza política que aún se encuentran sin solución, sea como resultado de la controversia, en consecuencia de la ausencia de diálogo entre los envueltos, o por omisión del Poder Público en relación a determinados temas relevantes. (Folena de Oliveira, 2016, p. 62)

En el juicio de los embargos de declaración ocurrido en octubre de 2013 (Barroso, 2013), como respuesta a los cuestionamientos y dudas lanzadas para cumplir la decisión de desocupación de los invasores del área de la Reserva Indígena $R a$ posa Serra do Sol, formuladas por el Senador Mozarildo Cavalcanti, el Supremo Tribunal Federal entendió que:

a. Como ya había sido resaltado en el juicio de la Petición 3.388/RR, para determinar si las personas mestizadas o aquellas que viven maritalmente con indios pueden explotar el usufructo indígena, ya que se adoptó el criterio sociocultural en el juicio, se decidió que dichas personas "pueden permanecer en el área demarcada y valerse del usufructo exclusivo para todos aquellos que integran las comunidades indígenas locales. (...) lo que interesa es su comunión con el modo de vida tradicional de los indios de la región" (Barroso, 2013).

b. En relación con si las autoridades religiosas o templos no indígenas deben permanecer en la región o ser destruidos, el Tribunal dispuso que:

Los propios indios deben decidir sobre su presente y su futuro - lo que se refiere tanto a la imposición de valores externos como a la prohibición de contacto con otros modos de vida. (...) será de responsabilidad de la Unión y del Ministerio Público organizar y supervisar la entrada, la permanencia y la construcción de templos en la Tierra Indígena Raposa Serra do Sol, tomando las medidas necesarias para que la elección de los grupos indígenas sea respetada en cada tiempo y para que a los no indios se les preserven sus derechos durante el periodo de permanencia. (Barroso, 2013)

c. Si las escuelas municipales y estatales pueden continuar en funcionamiento e impartir clases con un currículo dirigido a los no indígenas, el Tribunal manifestó que "es perfectamente viable el funcionamiento de estas escuelas, desde que sean respetadas las normas federales sobre la educación de los indios" (Barroso, 2013). 
d. Relacionado con la circulación por vías terrestres y fluviales de la región, se aclaró que "los indios no ejercen poder de Policía, ni pueden hacer inviable el tránsito de otras personas por las vías públicas que atraviesan el área demarcada" (Barroso, 2013).

e. Respecto a las acciones individuales en que se cuestiona la propiedad de buena fe, el tribunal respondió que, sobre "todos los procesos relacionados a esa tierra indígena (...) no podrán persistir pretensiones posesorias o de dominio de particulares, salvo si son bienhechurías derivadas de la ocupación de buena fe" (Barroso, 2013).

En lo que se refiere al recurso de embargos de declaración presentado por el Ministerio Público Federal, en la parte que cuestionó la validez de las condicionantes presentadas por el ministro Carlos Alberto Menezes Direito (Direito, 2009), el Tribunal entendió que (Barroso, 2013):

Las condiciones no integran el objeto de lo que fue decidido y no hacen cosa juzgada material. Esto significa que la incidencia de las referidas directrices en la Reserva Raposa do Sol no podrá ser objeto de cuestionamiento en otros procesos. No fue por otra razón, que el Tribunal substituyó la improcedencia del pedido por la improcedencia parcial. (...) el acuerdo embargado ostenta la fuerza moral y persuasiva de una decisión de la más alta Corte del País, de la que se origina un elevado encargo argumentativo en los casos en que se cogita como superación de sus razones.

El Ministerio Público Federal también cuestionó, en su recurso, la prohibición de nuevas demarcaciones, prevista en la condicionante número 17 del voto del ministro Carlos Alberto Menezes Direito (Direito, 2009). No obstante, el Supremo Tribunal aclaró que "el procedimiento demarcatorio que redundó en la demarcación de la tierra indígena Raposa Serra do Sol no podrá ser revisado, considerando su corrección formal y material atestada por este Supremo Tribunal Federal." (Barroso, 2013)

Entonces, en tesis, la prohibición de ampliar nuevas demarcaciones estaría limitada apenas al caso de la Reserva Indígena Raposa Serra do Sol. Sin embargo, "la fuerza moral y persuasiva de una decisión de la más alta Corte del País" (Barroso, 2013) parece no ser suficiente, a medida que la redacción de la referida condicionante parece ser extensible a todos los casos de reservas indígenas existentes en el país, lo que aún deja muchas dudas en el aire. 
Al analizar el recurso de embargos de declaración de las comunidades indígenas tanto del usufructo como del aprovechamiento de los yacimientos minerales y de los ríos y lagos del área demarcada, el Tribunal acogió en parte tales embargos, para aclarar que:

El usufructo de los indios no les da el derecho a explotar recursos minerales (bienes públicos federales) sin autorización de la Unión, en términos de la ley específica (...). De todas formas, no se puede confundir la minería, con aquellas formas tradicionales de extractivismo, practicadas inmemorialmente, en las cuales la colecta constituye una expresión cultural o un elemento del modo de vida de determinadas comunidades indígenas. (Barroso, 2013)

Como se observa, de un lado, el Supremo Tribunal Federal dice que es responsabilidad de los indios el "destino de su presente y de su futuro" (Barroso, 2013); por otro lado, ellos permanecen totalmente tutelados por el aparato del Estado y pueden incluso ser desalojados de un lugar hacia otro, como ocurrió durante el régimen dictatorial de 1964-1985, cuando apuntaron los fusiles contra la resistencia indígena (Valente, 2017).

Esta situación es típica de una sociedad colonial, acostumbrada a convivir pacíficamente con las heridas de la crueldad haste los días actuales.

En lo referente a la cuestión indígena, lo absurdo está bien representado por la creación de la figura jurídica del "marco temporal" (Brito, 2009), por medio del cual el Supremo Tribunal Federal confirió el derecho de ocupación de la tierra solamente a los indígenas que estaban resistiendo contra la "expoliación renitente" de los invasores, y que se encontrasen en posesión de la tierra el día 5 de octubre de 1988 (fecha de la promulgación de la Constitución Federal de 1988). El marco así constituido, como magia, por la retórica, establece la más perfecta "radiografía" del sufrimiento y de la lucha de un pueblo tutelado e imposibilitado de hablar por sí mismo, incluso en los días de hoy.

Como afirma Gramsci (2014, p. 135) "los grupos subalternos sufren siempre la iniciativa de los grupos dominantes incluso cuando se revelan y sublevan: solo la victoria "permanente" rompe, y no inmediatamente, la subordinación".

En la causa de los pueblos indígenas, estas agrupaciones son consideradas subalternas porque siempre han estado a merced de la "iniciativa de los grupos dominantes", representada por la permanente tutela del aparato burocrático (en el cual está incluido el Supremo Tribunal Federal) de un Estado al servicio de la clase 
dominante, que marginaliza y masacra, desde hace 519 años, a ascendientes y a descendientes del pueblo ancestral aquí encontrado en el año 1500.

Continuando con Gramsci (y que se aplica a la cuestión de las tierras de los pueblos indígenas), y como se observa en el juicio realizado por el Supremo Tribunal Federal sobre la Reserva Indígena Raposa Serra do Sol, "incluso cuando parecen victoriosos, los grupos subalternos están a la defensiva, bajo alerta" (Gramsci, 2014, p. 135), puesto que la estructura del Estado está constituida para marginalizarlos eternamente y someterlos a todo tipo de violencia.

\section{5) La convivencia pacífica con la crueldad}

A pesar de la aparente victoria contra los autores de la acción popular, que cuestionaban los actos administrativos de demarcación y homologación de la Reserva Indígena Raposa Serra do Sol, en el Supremo Tribunal Federal, la lucha de los indios, como grupo subalterno, necesita ser permanente, ya que, cada vez con más frecuencia, está allá el cuerpo extendido en el suelo de más de un indígena postrado en una batalla sin tregua por el derecho a su tierra, en un contexto desigual, que niega todo un pasado de exterminio y saqueos practicados contra un pueblo. En el ámbito indígena, negar la crueldad de las masacres y de la expulsión violenta de las tierras, amparadas por el Estado y por particulares, además de observar todo con normalidad, pasividad y naturalidad por el Supremo Tribunal Federal, es una forma típica de aceptación colonial.

En el juicio del caso de la comunidad indígena Guyraroká, el ministro Gilmar Mendes, en su voto conductor del acuerdo, afirmó, sin ninguna medida, que "los primeros propietarios adquirieron las tierras junto al Gobierno del Estado de Mato Groso, a través de compra y, paulatinamente, expulsaron a los indios, práctica común en aquella época" (Mendes, 2014).

Efectivamente, la expulsión de los indios de sus tierras no es vista, por los jueces del Supremo Tribunal Federal, como un acto repulsivo al derecho; al contrario, los actos de violencia practicados contra los pueblos indígenas han favorecido a los invasores de tierras. Los componentes del Tribunal utilizan como argumento desfavorable a los indígenas el "hecho" de "no haber resistencia por parte de ellos", lo que caracteriza la expoliación renitente y así, por orden jurídica, mantienen a los invasores en posesión de tierra: al final, "los indios fueron expulsados de sus tierras, ipero no hicieron nada!”. 
El ministro Eros Grau, en su voto en el caso de la reserva Caramuru-Catarina-Paraguaçu, reconoció que los indios (Pataxós Hã-hã-hãe, Sapuyá, Baenã, Kariri y Kamakã) fueron expulsados de sus tierras mediante la aplicación de diversas formas de violencia, "desde la quemada de malocas, destrucción de plantaciones y castigos físicos, morales y psicológicos". (Grau, 2012) Es decir, la mera expulsión no fue suficiente, partieron para la tortura física y moral, bajo la protección del aparato estatal.

Sobre el caso anterior, la ministra Carmen Lúcia expuso en su voto que "fue la Unión que, por la actuación del Servicio de Protección al Indio, en las décadas de cincuenta y sesenta, arrendó glebas de tierras en el área de la reserva" (Lúcia, 2012) y continúa diciendo:

Los últimos indígenas restantes del Puesto Catarina-Paraguaçu habrían sido obligados a dejar el local, esparciéndose por el extremo sur de Bahia, donde algunas familias fueron conducidas (transferidas) hacia la Hacienda Guarani, en el municipio de Carmésia, en Minas Gerais. (Lúcia, 2012)

Se nota, como manifestó Carmen Lúcia, que la violencia contra los indios parte del aparato estatal, que debería protegerlos, pero es utilizado para defender los intereses privados de los invasores, como han reconocido los ministros del Supremo Tribunal Federal. Sin embargo, delante de la violencia reconocida, el Supremo Tribunal Federal — como integrante del aparato Estatal - convive pacíficamente con los actos de crueldad practicados contra los pueblos indígenas.

Así, se hace evidente el cuadro de perversidad de un colonialismo fuertemente presente en los juicios, ya que los jueces del Supremo Tribunal Federal demuestran no tener percepción de humanidad, delante de los gravísimos actos perpetrados contra los pueblos indígenas (expulsados de sus tierras, como lo reconoce el mismo Tribunal). Todo esto nos hace recordar el ejemplo de Fanon, cuando hace mención del comportamiento del negro que desea ser blanco (Fanon, 2008, p. 27); lo que, en el caso del Supremo Tribunal Federal, es juzgar como si fuera una corte constitucional europea o americana, olvidándose de que está en un país colonizado.

Tribunales, jueces, legisladores y administradores públicos se comportan como si estuvieran tratando la remoción de cosas abstractamente consideradas, pero no es así, estamos hablando de miles/millones de vidas, de seres humanos que sienten, sufren, lloran, sangran y producen cultura. Son personas que, en calidad de pueblos originarios, aquí se encontraban mucho antes de la llegada del colonizador y, por eso, tienen todo el derecho a ocupar la tierra. 


\section{6) La radiografía del colonialismo}

Durante el juicio de la Reserva Indígena Raposa Serra do Sol, el Supremo Tribunal Federal fijó, de forma metafísica, el "marco temporal" relativo a la ocupación de los indígenas sobre sus tierras, considerado la fecha de lapromulgación de la Constitución de 1988 (5 de octubre), "para el reconocimiento de los derechos originarios sobre las tierras que tradicionalmente ocupan los indios" (Britto, 2009).

Para el relator del proceso, Ayres de Britto, "el entrar en vigor de la nueva Ley Fundamental Brasileña es la radiografía de la situación indígena en ese delicado tema de ocupación de tierras a demarcar, por la Unión, la posesión permanente y el usufructo exclusivo de esa o de aquella etnia aborigen" (Brito, 2009).

En realidad, sin que la Constitución defina una línea al respecto del citado marco temporal, el Supremo Tribunal Federal, de inteligencia y superioridad exclusiva de sus jueces, negó la existencia de pueblos indígenas, anteriormente, a cualquier Constitución del Estado brasileño, llegando incluso a rechazar masacres y expulsiones de las tierras que les pertenecían antes de la llegada de los europeos al continente americano.

Sobre este asunto, Carlos Alberto Menezes Direito, en su voto, manifestó que era necesaria "la presencia constante y permanente" (Direito, 2009) de los indios sobre la tierra; y, para Ayres Britto, la posesión de los indígenas sobre la tierra exige "continuidad suficiente" (Britto, 2009).

Los jueces del Supremo Tribunal Federal, por medio de la inventada "radiografía", niegan el "renitente" proceso colonialista, que ha eliminado la cultura indígena y ha impedido la "presencia constante y permanente" de ellos en nuestro medio, como condicionó Menezes Direito. (Direito, 2009)

Asimismo, exigir la ocurrencia de "continuidad suficiente" de los indios sobre la tierra, como expresó en su voto Ayres de Britto, es lo mismo que negar el exterminio y los saqueos realizados contra los nativos en más de 500 años; la posición de los ministros del Supremo Tribunal Federal solamente ratifica la presencia del colonialismo en pleno siglo XXI, ejercido por la más alta Corte de Justicia.

Vale resaltar que las características patológicas de perversidad inherentes al colonialismo "El bienestar y el progreso de Europa han sido construidos con el sudor y los cadáveres de negros, árabes, indios y amarillos" (Fanon, 1968, p. 77) se manifiestan en Gilmar Mendes, en el juicio del caso de la Tierra Indígena Guyraroká, cuando dicho ministro condujo su voto a favor de los hacendados, a pesar 
de reconocer que los indios fueron expulsados y desalojados de sus tierras: "la población Kaiowá residió en la tierra reivindicada hasta el inicio de la década de 1940 y que, 'a partir de esa época, las presiones de los hacendados que comenzaron a comprar las tierras en la región hicieron inviable la permanencia de indios en el local" (Mendes, 2014).

Siguiendo la misma característica de patología del colonialismo, Teori Albino Zavascki, en el caso Tierra Indígena Limão Verde, expresó, continuando la orientación del juicio del caso Raposa Serra do Sol, que "no se incluyen en ese concepto de tierras indígenas aquellas ocupadas por ellos en el pasado ni las que sean ocupadas en el futuro" (Teori, 2014), con la finalidad de garantizar la reintegración de posesión sobre los territorios invadidos o tomados de los indios.

Por las palabras de Zavascki ninguna tierra jamás pertenecerá a los indios, porque, para reconocer su derecho, ellos tendrían que haberlas ocupado el día 5 de octubre de 1988. Así, los que fueron desalojados o expulsados de sus tierras, antes de aquella fecha, no tienen ningún derecho y los que fueron expulsados después de aquel día tampoco. La triste conclusión es que los Guaranis, que viven en busca de la "Tierra sin mal" (Ivy marãey), jamás tendrán su merecido descanso en Brasil.

La posición del Supremo Tribunal Federal, a partir del juicio del caso Raposa Serra do Sol, en marzo de 2009, establece una nueva forma de negación de la existencia de los pueblos indígenas; su visión es resultado del proceso de colonización, que aún continúa válido y presente, mientras que los indios solo tienen derecho a la posesión de la tierra que estuviesen ocupando el día en que la Constitución fue promulgada (el 5 de octubre de 1988). De este modo, se les niega toda posibilidad de apoderamiento de sus tierras, de las cuales fueron expulsados en el pasado y de las que ocupen en el futuro.

En el caso Raposa Serra do Sol, solamente se les aseguró el derecho a la posesión, porque, en la fecha en la cual se promulgó la Constitución, "la reocupación no ocurrió apenas por efecto de expoliación renitente por parte de los no indios (invasores)"'(Britto, 2009), ya que la ocupación indebida de las tierras por posesores, situadas en la tierra indígena Raposa Serra do Sol, "no impidió, a los indios (de la región), su capacidad de resistencia y afirmación de su peculiar presencia en todo el complejo geográfico de 'Raposa Serra do Sol'. (Britto, 2009)

Como consecuencia, el ministro relator Ayres de Britto, en su voto expuso que, además de la determinación del marco temporal de la ocupación de la tierra por los indios el 5 de octubre de 1988 : 
No basta que la ocupación agraria sea coincidente con el día y el año de la promulgación, es necesario que exista la 'perdurabilidad de la ocupación indígena, en el sentido anímico y psíquico, ya que vivir en determinadas tierras significa pertenecer a ellas como ellas pertenecen a ellos, a los indios. (Britto, 2009)

Ese fue el camino utilizado por el Supremo Tribunal Federal para dificultarles la posesión de tierra a los indígenas, expulsados o desalojados, y establecer que dicha posesión sería equivalente a una "radiografía", la de poseer sobre la tierra un sentimiento psíquico de pertenencia. De este modo, el Supremo Tribunal Federal, abrió puertas que impiden que los indios recuperen la posesión de los territorios antes ocupados por ellos.

Tanto que, en el juicio del caso de la comunidad indígena Guyraroká, ocurrido en septiembre de 2014, el ministro Gilmar Mendes, a través de su voto, maniobró el "acordão", gran acuerdo vencedor, afirmando que (Mendes, 2014) "el marco temporal se relaciona a la existencia de la comunidad indígena y a la efectiva y formal ocupación agraria. En caso contrario, de nada serviría establecer tales límites" (marco temporal, 5 de octubre de 1988, fecha de la promulgación de la Constitución).

O sea, las condicionantes, como el marco temporal, fueron una creación espiritual para establecer la "paz agraria", desde el punto de vista del Supremo Tribunal Federal, negando el desalojo y la masacre promovidos contra los pueblos indígenas en el pasado; siendo evidente que la victoria de los indios, en el caso Raposa Serra do Sol, representó una derrota para los demás indígenas, expulsados de sus tierras antes y después del 5 de octubre de 1988.

Es importante destacar lo que expresó Gilmar Mendes, en su voto relativo a la comunidad indígena Guyraroká (Mendes, 2014), que los adquirientes (propietarios de tierras compradas de Estados federados, como ocurrió en Mato Groso) expulsaron a los indígenas de aquellas tierras, práctica común, según el STF, de aquella época. Sin embargo, aunque explícitamente se reconozca la expulsión forzada, el Supremo Tribunal Federal — por la creación retórica del marco temporal- impidió su retorno a la tierra ocupada en el pasado, pues, en caso contrario, tendría que, según el voto de Gilmar Mendes, "aceptar la demarcación de tierras en áreas donde están situadas antiguas aldeas indígenas en grandes ciudades de Brasil" (Mendes, 2014). Lo anterior significa que es una gran excusa para justificar la suspensión de cualquier demarcación de tierra indígena, como lo ha hecho el Gobierno de Michel Temer, denunciado por el Consejo Indigenista Misionero y el Consejo de las Naciones Unidas. 
La teoría del marco temporal ha evolucionado en el Supremo Tribunal Federal; tanto que Teori Zavascki cambió su postura anterior, en el caso de la Tierra Indígena Capim Limão (Teori, 2014), por entender que, después de realizado el juicio del Mandato de Seguridad número 29.087, relatado por el ministro Gilmar Mendes, el 16/9/2014 (Mendes, 2014), concluyó de forma diversa respecto al conflicto, a partir de la definición de la condicionante del marco temporal, relativo a la ocupación efectiva de la tierra indígena, establecido el 5/10/1988 (fecha de la promulgación de la Constitución), definido en el juicio del caso Raposa Serra do Sol (PET 3.388), bajo el argumento de que

Así, no se incluyen en el concepto de tierras indígenas aquellas ocupadas por ellos en el pasado, ni las que se ocupen en el futuro. (...) Tierras que tradicionalmente ocupan, aténtese, y no aquellas que se ocupen. Tampoco las tierras ya ocupadas en otras épocas, sin continuidad suficiente para alcanzar el marco objetivo del día 5 de octubre de 1988. (...) la fecha de verificación del hecho en sí de la ocupación agraria es el día 5 de octubre de 1988, y ninguna otra. (...) radiografía de la situación indígena en ese delicado tema de ocupación de las tierras a demarcar por la Unión para la posesión permanente y el usufructo exclusivo de ese o de aquel aborigen. (Teori, 2014)

Por el sumario 650 del Supremo Tribunal Federal, se firmó el entendimiento de que las "tierras tradicionalmente ocupadas por los indios no abarcan las que fueron ocupadas en el pasado"; habiendo evolucionado esta jurisprudencia para negar también las tierras ocupadas indebidamente después del 5 de octubre de 1988. Como se ve, el Supremo Tribunal Federal atribuyó a los indígenas ("tutelados" por el Estado brasileño, que los considera "incapaces") la obligación de resistir (e incluso de proponer una acción judicial de reintegración de posesión) contra quienes los expulsaron de la tierra bajo el fundamento "título de propiedad" concedido por el propio Estado.

Esta absurda ficción justifica toda la forma de desapropiamiento de las tierras contra los indígenas, quienes, por la formulación judicial presentada por el Supremo Tribunal Federal, jamás tendrán condiciones de recuperar sus territorios, ocupados por la violencia sistematizada en crueldad desde el inicio de la colonización de Brasil, que perdura hasta hoy.

\section{7) La posesión precaria es suya, pero quien manda somos nosotros}

En el juicio del caso Raposa Serra do Sol, se estableció que los indios no pueden "bloquear carreteras, cobrar peajes por el uso de ellas ni inhibir el regular 
funcionamiento de las reparticiones públicas", estipulándose que las instituciones del Estado brasileño (como Fuerzas Armadas y Policía Federal) estén presentes en las áreas, con el fin de:

Concienciar aún más a nuestros indígenas para, instruirlos (a partir de los conscriptos), alertarlos contra la influencia eventualmente maldadosa de ciertas organizaciones no gubernamentales extranjeras, movilizarlos en defensa de la soberanía nacional y reforzarles el sentimiento innato de brasilidad. (Britto, 2009)

Así, el Estado brasileño, sin llevar en cuenta la voluntad de los indios - mantenidos como tutelados- detiene el total control del territorio del país y ejerce influencia sobre su cultura, como se realizó durante el proceso de colonización portuguesa, en el que los pueblos indígenas fueron utilizados para guerrear a favor del colonizador.

En el juicio del caso de la reserva Caramuru-Catarina-Paraguaçu (Fux, 2012), en la región sur, Estado de Bahía, el Supremo Tribunal Federal apenas reconoció la nulidad de los títulos de propiedad de los hacendados sobre las áreas localizadas dentro de la reserva; sin embargo, no pudo reconocerles a los indios el derecho a la demarcación de las nuevas áreas, más allá de las ya reconocidas en 1938.

Con respecto a esto, el Estado de Bahía concedió títulos de propiedad en áreas indígenas, que abarcan parte del territorio de diversos municipios al sur del lugar. La Fundación Nacional del Indio (FUNAI) buscó, mediante acción judicial propuesta en el Supremo Tribunal Federal, declarar la nulidad de los títulos de propiedad de los inmuebles rurales, concedidos por el Estado de Bahía, que están en el área de la reserva Caramuru-Catarina-Paraguaçu, declarada, en 1938, "en los Municipios de Conquista, Itambé, Itapetinga, Canavieiras, Itabuna, Pau Brasil e Itajú de Colonia"; la FUNAI sostuvo que "los indios no abandonaron el local por voluntad propia" (Fux, 2012).

El Supremo Tribunal Federal reconoció que los indios (Pataxós Hã-hã-hãe, Sapuyá, Baenã, Kariri y Kamakã) fueron expulsados de sus tierras mediante el uso de diversas formas de violencia, "desde la quemada de malocas, destrucción de plantaciones y castigos físicos, morales y psicológicos" (Grau, 2012).

El ministro Eros Grau juzgó procedente el pedido de la FUNAI para declarar nulos todos los títulos de tierra en el área de la reserva. No obstante, la ministra Carmen Lúcia, en extenso voto-vista (Lúcia, 2012), limitó la declaración de nulidad de los títulos de los hacendados a las propiedades dentro del área de la reserva, 
que, según la pericia realizada en el proceso, constató ser de apenas 54000 hectáreas y no del área total reconocida en 1938 por el Servicio de Protección al Indio.

La ministra Carmen Lúcia reconoció que fue el poder público el causante del conflicto en el local, que culminó en violencia contra los indígenas, expulsados del área de la reserva: "fue la Unión que, por la actuación del Servicio de Protección al Indio en las décadas de cincuenta y sesenta, arrendó glebas de tierras en el área de la reserva declarada en 1938." (Lúcia, 2012) Y añadió que "los últimos indígenas remanentes del Puesto Catarina-Paraguaçu fueron obligados a dejar el local, dispersándose por el extremo sur de Bahía, conduciendo a algunas familias (removidas) a la 'Hacienda Guarani, en el municipio de Carmésia, en Minas Gerais"” (Lúcia, 2012).

Lúcia intentó justificar que la ausencia memorial de los indios en la reserva podría conducir al reconocimiento de la mantención de los hacendados en el local, ya que, "en el régimen constitucional de 1934 a 1946, la posesión indígena a ser respetada estaba condicionada al carácter de permanencia en la localización memorial establecida por el indio o como producto de definición del Órgano oficial con la atribución de cuidar sus intereses" (Lúcia, 2012). En este punto, la ministra Carmen Lúcia, casi puso en riesgo la reserva, bajo la alegación de ausencia de posesión permanente e inmemorial de los indios en el área pretendida, exponiendo que:

El objetivo de creación de la reserva indígena Caramuru-Catarina-Paraguaçu era garantizar el avance del frente agropastoril en la región sur de Bahia, con el asentamiento de los diversos grupos indígenas existentes, autóctonos y oriundos de aldeas extinguidas o situadas en otras localidades. (Lúcia, 2012)

Efectivamente, la reserva fue creada para fijar a los indios oriundos de áreas diversas y para permitir "el avance del frente agropastoril" (Lúcia, 2012). Esto es, a los indígenas los empujaron hacia otras áreas para abrirle camino a la agroindustria y el Supremo Tribunal Federal pasivamente aceptó y corroboró tamaño absurdo.

En este mismo juicio, la alegación de ausencia de posesión permanente hizo que el ministro Marco Aurélio de Mello votara contra los indígenas, por entender que

(...) no estamos aquí para cuidar del rescate, considerada la violencia perpetrada en las tres Américas — del Sur, Central y del Norte- contra los indígenas, porque sería, imposible el retorno, por orden natural de las cosas, al estado anterior, cuando los indígenas realmente ocupaban, con exclusividad, las áreas territoriales. (...) Brasil todo consubstanció, a partir 
del descubrimiento, las tierras indígenas. Ni por eso podemos pensar en la desocupación, para entregar el territorio nacional a los indígenas (...). (Mello, 2012)

Delante de estas reiteradas manifestaciones de los ministros del Supremo Tribunal Federal, se percibe que la jurisprudencia de la Corte fue creada para ofrecer una apariencia de seguridad a los indios, que ya están en territorios demarcados y homologados, de los que tienen la posesión precaria, pero quienes mandan son los colonizadores, los que en cualquier momento pueden removerlos de sus tierras; y que nada hace cuando los indios son despojados de sus territorios, a través de la violencia de los invasores.

\section{8) Conclusión}

En esta investigación, se ha verificado el comportamiento de un Supremo Tribunal Federal indiferente en relación con los indígenas, particularmente, considerando la crueldad con la que los indios brasileños fueron desalojados y expulsados de sus tierras ancestrales, mediante eventos practicados por invasores y el propio Estado.

Se puede afirmar que el comportamiento de los miembros del Supremo Tribunal Federal es el reflejo de una sociedad tan habituada a siglos de explotación que se ha vuelto incapaz de manifestar un gesto de repulsión delante del sufrimiento ajeno y acepta con pasividad la injusticia practicada contra sus semejantes.

En el caso brasileño, el colonialismo, tanto del pasado como del presente, trabaja en el exterminio de los pueblos indígenas para, de esta forma, expropiar sus tierras. Por eso, la decisión del Supremo Tribunal Federal, que estableció un célebre "marco temporal", no explicitado en el texto constitucional, niega todo un pasado histórico de violencias practicadas contra los indios, desalojados por acciones de Gobiernos o expulsados de sus tierras por invasores clandestinos, en una sucesión de actos coloniales, fundados en métodos de tortura física y moral.

Delante de todo esto, consideramos que la posición del Supremo Tribunal Federal acerca de la situación de las tierras indígenas, construida a partir del juicio de la Reserva Indígena Raposa Serra do Sol, ocurrido en marzo de 2009, y que está siendo reproducido en otros casos para negar el derecho de posesión sobre sus tierras ancestrales a los indios (como se demuestra en el estudio), constituye una durísima forma de negación de la existencia a los pueblos indígenas. 
Tomando en cuenta que el Supremo Tribunal Federal estableció que los indios solo tienen el derecho a la posesión de la tierra que estuviesen ocupando en la fecha en que la Constitución fue promulgada (el 5 de octubre de 1988), y que, por el referido marco constitucional, se les niega toda posibilidad de posesión sobre las tierras, de las cuales fueron expulsados y desalojados en el pasado, así como sobre las que puedan ocupar en el futuro, podemos afirmar que este posicionamiento del citado Tribunal es, sin duda, resultado del proceso de colonización, que aún continúa, válido y presente, impidiendo la madurez de la sociedad brasileña.

\section{Referencias}

Amado, J. (2008). Gabriela, cravo e canela. São Paulo: Companhia das Letras.

Amado, J. (2012). São Jorge dos Ilhéus. São Paulo: Companhia das Letras.

Amado, J. (s. f.). Terras do sem fim. São Paulo: Círculo do livro.

Barroso, L. R. (2013). Supremo Tribunal Federal (STF), Brasília. Embargos de declaración en la PET 3.388/RR. Fecha del juicio: 23/10/2013. Relator: Roberto Barroso.

Britto, C. A. (2009). Supremo Tribunal Federal (STF), Brasília. Petición 3.388/RR. Fecha del juicio: 19/3/2009. Relator: Min. Carlos Britto.

Calderón, M. A. (2016). Cuentos para un final. El indio. San José: Habib Succar.

Comissão Pastoral da Terra (CTP). (2018). Assassinatos no campo batem novo recorde e atingem maior número desde 2003. Relatório Massacres no Campo. Recuperado de: https://www.cptnacional.org.br/publicacoes2/destaque/4319-assassinatos-no-campo-batem-novo-recorde-e-atingem-maiornumero-desde-2003.

Consejo Indigenista Misionero (CIMI). (2016). Relatório Violência contra os povos indigenistas no Brasil. Recuperado de: https://www.cimi.org.br/pub/Relatorio2016/ relatorio2016.pdf

Direito, C.A.M. (2009). Supremo Tribunal Federal (STF), Brasília. Petición 3.388/RR. Fecha del juicio: 19/3/2009. Relator: Min. Carlos Britto

Fanon, F. (1968). Os condenados da terra. Río de Janeiro: Civilização Brasileira.

Fanon, F. (2008). Pele negra, máscara branca. Salvador: Editora da Universidade Federal da Bahia.

Fedorov, A. y Srapyan, E. (2018). O melhor lugar para ser criança e envelhecer é na América Latina. Sputniknews. Recuperado de: https://br.sputniknews.com/ americas/2018020710465968-amazonas-melhor-lugar-domundo-fotos/ 
Fux, L. (2012). Supremo Tribunal Federal (STF), Brasília. Acción Civil Originaria número 312/BA. Fecha del juicio: 2/5/2012. Relator: Luiz Fux.

Fux, L. (2017). Supremo Tribunal Federal (STF), Brasília. Agravo en Recurso Extraordinario número 1.017.484/MS. Fecha del juicio: 12/5/2017. Relator: Luiz Fux

Folena de Oliveira, J. R. (2016). Intervenção judicial. Río de Janeiro: Senge/RJ.

Gramsci, A. (2014). Cadernos no Cárcere. Río de Janeiro: Civilização Brasileira.

Grau, E. (2012). Supremo Tribunal Federal (STF), Brasília. Acción Civil Originaria número 312/BA. Fecha del juicio: 2/5/2012. Relator: Luiz Fux.

Hage, F. A. S., Peixoto, M. y Vieira Filho, J. E. R. (Junio de 2012). Aquisição de terras por estrangeiro no Brasil: uma avaliação jurídica e econômica. Texto para discussão 114. Brasília: Núcleo de Estudo e Pesquisa do Senado Federal. Recuperado de: https://www12.senado.leg.br/publicacoes/estudos-legislativos/tiposde-estudos/textos-para-discussao/td-114-aquisicao-de-terras-por-estrangeiros-nobrasil-uma-avaliacao-juridica-e-economica

Hegel, G. W. F. (2010). Filosofia do direito. São Leopoldo: Editora Unisinos.

Kudel, S. (2017). Sámi culture. Bluewings, 30-39. Helsinki.

Leal, V. N. (2012). Coronelismo, enxada e voto: o município e o regime representativo no Brasil. São Paulo: Companhia das Letras.

Linharaes, M. Y. y Teixeira da Silva, F. C. (1999). Terra prometida: uma história da questão agrária no Brasil. Río de Janeiro: Editora Campus.

Lúcia, Cármen. (2012) Supremo Tribunal Federal (STF), Brasília. Acción Civil Originaria número 312/BA. Fecha del juicio: 2/5/2012. Relator: Luiz Fux.

Mello, M. (2012). Supremo Tribunal Federal (STF), Brasília. Acción Civil Originaria número 312/BA. Fecha del juicio: 2/5/2012. Relator: Luiz Fux.

Mendes, G. (2014) Supremo Tribunal Federal (STF), Brasília.. Mandado de Seguridad número 29.087, Fecha del juicio: 16/9/2014. Relator Gilmar Mendes.

Mendes, G. (2016). Supremo Tribunal Federal (STF), Brasília. Embargos de Declaración en el Recurso Ordinario del Mandato de Seguridad número 29.087 ED-ED/DF. Fecha del juicio: 8/3/2016. Relator: Gilmar Mendes.

Miranda, M. (2005). Pontes entre povos. São Paulo: SESC.

Organización de Naciones Unidas (ONU). (2016). Relatório da missão especial ao Brasil da relatora especial sobre os direitos dos povos indígenas. 
Recuperado de: http://unsr.vxtaulicorpuz.org/site/index.php/es/documentos/ countryreports/154-report-brazil-2016

Scorza, M. (1973). Bom dia para os defuntos. Río de Janeiro: Civilização Brasileira.

Silveira, N. (1983). Supremo Tribunal Federal (STF), Brasília. Acción Civil Originaria 278/MT. Fecha del juicio: 10/8/1983. Relator: Min. Soares Munoz.

Teori. Z. Supremo Tribunal Federal (STF), Brasília. Agravo Regimental en Recurso Extraordinario número 803.462/MS. Fecha del juicio: 9/12/2014. Relator Teori Zavascki

Valente, R. (2017). Os fuzis e as flechas. História de sangue e resistência indigena na ditadura. São Paulo: Companhia das Letras. 